Sharif University of Technology
Scientia Iranica
Transactions A: Civil Engineering
IRAENTIA
IRttp://scientiairanica.sharif.edu

\title{
Specimen preparation methods for artificially cemented sand in simple shear and hollow cylinder apparatuses
}

\author{
K. Fakharian ${ }^{\mathrm{a}, *}$, A.H. Eghbali ${ }^{\mathrm{b}}$, S. Heidari Golafzani ${ }^{\mathrm{a}}$, and M.R. Khanmohamadi ${ }^{\mathrm{a}}$ \\ a. Department of Civil and Environmental Engineering, Amirkabir University of Technology, Tehran, P.O. Box 1591634311, Iran. \\ b. Department of Engineering, Islamshahr Branch, Islamic Azad University, Tehran, P.O. Box 33147-67653, Iran. (Former PhD \\ student of Amirkabir University of Technology, Tehran, Iran.)
}

Received 11 March 2015; received in revised form 28 May 2016; accepted 26 September 2016

\author{
KEYWORDS \\ Specimen preparation; \\ Anisotropy; \\ Portland cement; \\ Stress path; \\ Simple shear; \\ Torsional hollow \\ cylinder; \\ Principal stress \\ rotation.
}

\begin{abstract}
Portland cement can be mixed with sand to improve its mechanical characteristics. Considering the inherent anisotropy of most sands, it is not clear whether the added cement shall contribute to equal increases in strength and stiffness in vertical and horizontal directions or not. Literature review reveals that all the previous experimental studies on the cement-treated soil topics are limited to conventional triaxial device test results. The effect of cement addition to clean sand in more sophisticated stress-path controlled devices like "Simple Shear Apparatus" (SSA) and "Hollow Cylinder Apparatus" (HCA) for simulating more realistic loading conditions, such as earthquake, have not been investigated yet. This paper presents innovative methods for testing artificially cemented sands through making modifications to the loading platens, specimen molds, and specimen preparation methods of SSA and HCA. Undrained tests under different monotonic stress paths were carried out on different mixtures of Portland cement with clean sand to investigate the effect of principal stress rotations. The test results revealed that the cement mixture reduces the anisotropy, while it improves the mixture mechanical properties compared to the compacted uncemented sand.
\end{abstract}

(C) 2018 Sharif University of Technology. All rights reserved.

\section{Introduction}

One of the important geomechanical aspects in relation to granular soils, like sand that causes major variations in the soil behavior characteristics, such as strength and deformation parameters, is cementation. In geotechnical en gineering, study of cementation is significant with regards to: (1) its effect on shear strength and soil behavior of natural cemented deposits, and (2)

*. Corresponding author. Tel.: +982164543003; Fax: +982122263432

E-mail addresses: kfakhari@aut.ac.ir (K. Fakharian); ah_eghbali@yahoo.com (A.H. Eghbali)

doi: $10.24200 /$ sci.2017.4177 application of cementing materials in the treatment of weak soils. Using the soil-cement mixture method has proven successful in various projects such as construction of the base layers of highway pavements, slope protection of earth dams, constructing load-bearing layer beneath shallow foundations, reducing sand liquefaction risks, and achieving significant reduction in the earth pressure behind retaining walls.

Review of literature reveals that extensive experimental research has been conducted in studying the behavior of treated sands with Portland cement; however, they have all been performed using triaxial devices. A few examples include Dupas and Pecker [1], Haeri et al. [2-3], Hamidi and Haeri [4], Schnaid et al. [5], Consoli et al. [6-10], Rotta et al. [11], and Malandraki and Toll [12]. To study the behavior of 
clean sands under cyclic loads like earthquake, SSA simulates more realistic stress states. Extensive studies have been reported on monotonic and cyclic behavior of sands using various types of SSA (e.g., Boulanger et al. [13], Vaid and Finn [14], Dyvic et al. [15], and Ishihara and Yamazaki [16]). However, no study has been reported in literature using SSA to evaluate the behavior of cemented sands. One reason might be the difficulty in establishment of complete at-rest $K_{0}$ condition at the interface of the sample mold vertical edge with prefabricated specimens. The second reason is the shortcomings associated with non-uniform stress distributions in SSA specimen during loading.

Moreover, considering the anisotropic behavior of clean sand under different stress paths, various advanced laboratory apparatuses, like (torsional) Hollow Cylinder Apparatus (HCA), have been developed to capture the anisotropy effects. Such studies mostly focus on the rotation of principal stresses ( $\alpha$ parameter) and intermediate principal stress parameter $(b)$ (e.g. Vaid et al. [17], Yoshimine et al. [18], Yang et al. [19], Bahadori et al. [20], Kumruzzaman and Yin [21], Sivathayalan et al. [22], Baziar and Sharafi [23], Baziar et al. [24], Jafarian et al. [25], and Keyhani and Haeri [26]). Considering that the studies on cemented sands have mostly been limited to triaxial and direct shear devices, evaluation of the artificially cemented sand behavior in more sophisticated apparatuses, such as HCA, capable of simulating anisotropy in a wide range of $\alpha$ values would be significant as it demonstrates the effect of added cement on the anisotropic mechanical behavior of the base soil.

The main obstacle in conducting SSA and HCA tests on cemented sands was how to prepare the specimens and whether the existing loading platens and molds were capable of performing the tests. It was soon found out that the conventional molds for preparing clean sand were not suitable to prepare and test artificially cemented sand specimens. Therefore, modifications were required.

This research deals with description and proposal of new and repeatable methods of artificially cemented sand specimen preparation for testing in SSA and HCA systems. Through time consuming stages and by trial and errors, modifications were made to SSA and HCA and their loading system as well as the specimen molds in order to allow for testing the cemented specimens. The efforts eventually led to developing new methods and procedures of performing the tests on the artificially cemented specimens in SSA and HCA.

The details of specimen preparation for cemented sands are presented for both SSA and HCA first, followed by some preliminary test results to highlight the effects of the principle effective stress rotation on the sand-cement mixture behavior.

\section{Apparatuses}

\subsection{Simple Shear Apparatus (SSA)}

The Simple Shear Apparatus (SSA) developed at Amirkabir University of Technology (AUT) was used in this research. The specimen container in this apparatus could be of NGI reinforced membrane type or Japanese annular ring type (Ishihara type).

Hydraulic jacks are controlled by an advanced closed-loop system, either load-controlled or displacement-controlled, utilizing a servo system to apply the tangential and normal loads to the specimen. Total of two load cells were used, with a capacity of $25 \mathrm{kN}$ in the vertical and $13 \mathrm{kN}$ in the horizontal directions. Two LVDTs with strokes equivalent to $25 \mathrm{~mm}$ were used to measure the vertical and horizontal displacements.

Due to the problems the previous researchers (e.g., Boulanger and Seed [27]) encountered, the proposed method by Vaid and Finn [14] might be used to assure a better precision. The problems with former studies were mainly because of the effect of excess pore water pressure in the simple shear specimen. The Vaid and Finn method simulates the boundary conditions of the undrained test along with the assumption of "constant volume". An air-dried sand specimen would be sufficient to use. In this method, if one can maintain the plan view cross section and vertical strains of the specimen constant (so-called "constant height" or "constant volume") during application of the shear, saturation of the specimen would no longer be required. This methodology has been evaluated by other researchers such as Dyvik et al. [15]; their results showed to have minor differences with the results of the actual undrained tests.

\subsection{Hollow Cylinder Apparatus (HCA)}

The available fully automated Hollow Cylinder Apparatus (HCA) at AUT soil dynamics lab was used in this study. This apparatus had digital closed-loop control servo motors equipped with 5 independent paths of imposing the force for application of the torque, vertical load, inner pressure, cell pressure, and backpressure, all of which were controlled hydraulically with oil pressure.

The apparatus had the capability of applying a torsional load in the order of \pm 225 N.m and an axial force up to $\pm 100 \mathrm{kN}$ for the range of cyclic loads in either of HCA-100 (outer diameter of $100 \mathrm{~mm}$ ) or HCA-150 (outer diameter of $150 \mathrm{~mm}$ ). Also, confining pressure, pore pressure/back pressure, and internal pressure of up to $1000 \mathrm{kPa}$ might be controlled by servos. Having an angular deformation sensor with deformation amplitude of $\pm 25^{\circ}$ for measuring large shear strains up to $\pm 40^{\circ}$ was another capability of the AUT-HCA. Stroke of LVDTs, which was used in this apparatus, was $100 \mathrm{~mm}$. 


\section{Materials}

Firoozkuh F161 crushed clean sand was selected as the base soil. This silica sand, which is classified as SP in the USCS, is a commercial artificially crushed sand with sub-angular to angular grains and is completely well-known and documented in the academic research of Iran (e.g., [20-29]). Physical properties of the base soil are presented in Table 1 and the grain size distribution curve is shown in Figure 1.

The amounts of cement added to the SSA specimens were $1.5,3$, and $5 \%$ of the sand weight and $3 \%$ for HCA specimens. Since study of the effects of cement adding is mainly aimed at improvement of the behavior of loose sands, the final relative density $\left(D_{r}\right)$ of the base soil specimen was selected approximately 10 to $15 \%$, based on which the densities of specimens were calculated. However, given that adding the small cement grains would increase the initial density of specimen, in accordance with the methods proposed by Ismail et al. [30] and Consoli et al. [10], the weight ratio of cement to clean sand was determined such that the final density of all treated specimens with cement was constant and equivalent to the density of the base soil specimens.

\section{Specimen preparation method}

All specimens in this research were made using wet tamping method. In order to obtain specimens of uniform density in height, all specimens were made using

Table 1. Physical properties of Firoozkuh sand (F161).

\begin{tabular}{cc}
\hline Properties & Amount \\
\hline$G_{s}$ & 2.65 \\
$e_{\max }$ & 0.86 \\
$e_{\min }$ & 0.58 \\
$D_{50}(\mathrm{~mm})$ & 0.26 \\
$C_{u}$ & 1.9 \\
$C_{c}$ & 0.88 \\
\hline
\end{tabular}

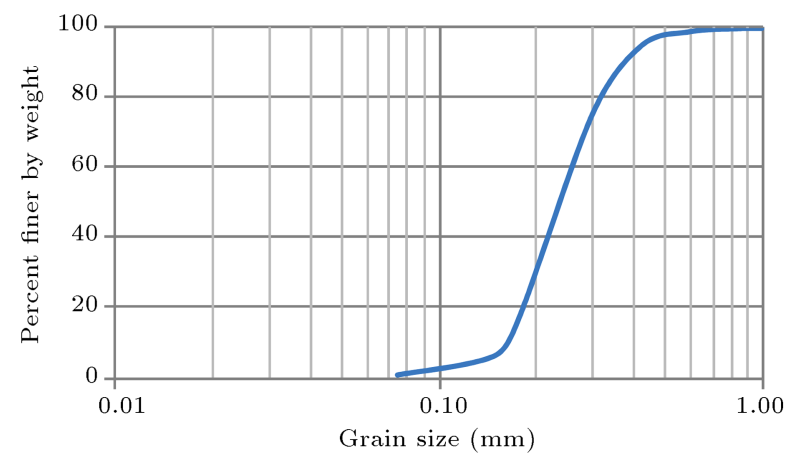

Figure 1. Grain size distribution curve of Firoozkuh Sand (F161). the under-compaction method with reduced density in accordance with the method proposed by Ladd [31]. For a better bonding between various layers, the former compacted layer surface was scratched after reaching the intended height. This way, a better bonding was provided with the subsequent layer at their joint surface.

Cement treated specimens were made by adding a pre-defined percentage of cement to the weight ratio of the base soil, dry mixing by hand, and finally adding the required moisture and remixing in identical layers. The required moisture is calculated as the moisture required for compaction of clean sand grains at a specified energy level and known compaction level ( $w=5 \%$ in all specimens) plus the net required amount of water for just hydration of cement grains equivalent to $\mathrm{W} / \mathrm{C}$ of unity. However, $1 \mathrm{ml}$ of water was added to the mixture of each layer to compensate for the water evaporation effects due to friction heat and absorbing by the batching container side wall during mixing. The cement treated specimens in all tests were placed into molds without application of surcharge loads and then kept in water-proof bags (to prevent evaporation of the moisture inside the specimen) for 28 days in a moist environment (water bathtub). More details of sample preparation for each of the devices are presented in the following subsections.

\subsection{SSA Specimens}

The molds known as the Japanese method [16] were used for testing the specimens of the base soil. In this type of mold, the soil specimen is placed in a rubber membrane, which is laterally confined by a set of thin aluminum rings ( $2 \mathrm{~mm}$ thick here). The diameter and height of simple shear specimens were $71 \mathrm{~mm}$ and $20 \mathrm{~mm}$, respectively. The reasons behind choosing this height were to minimize the effects of rocking motion and errors associated with them, to comply with the limitations of ASTMD6528-00 standard, and to satisfy the minimum required height.

Considering that the base soil specimen is compacted in the space confined by the aluminum rings, atrest $K_{0}$ condition is ensured with a good precision. In addition, these rings provide the plane strain condition (vertical boundaries remain planar and area is constant during shearing), which is one of the main conditions of the simple shear test. Moreover, upper and lower platens, which are in contact with the surfaces of the base soil, are serrated in AUT-SSA to ensure sufficient friction and no sliding along the boundary surfaces of shear application, provided that they penetrate into the specimens.

To satisfy the above required boundary conditions during vertical and shear load application to the cemented specimens, the mold and specimen loading accessories need to be modified. The problematic condi- 
tions that could not be resolved if the same accessories of the conventional SSA are used are:

a) Sliding between the upper and lower surfaces of prefabricated cemented specimens and the apparatus loading platens;

b) Lack of fulfillment of at-rest condition.

The first problem is due to surface hardness of the cemented specimens, which prevents the serrated surfaces of the top and bottom platens to penetrate into the specimen and, thus, a significant sliding is observed between the contact surfaces. The second problem results from the precast nature of specimens in which the diameter must be exactly equal to the inner diameter of the space confined between the rings and rubber membrane inside the rings. The specimen diameter needs to be adjusted in casting in such a way that no space would be left between sidewalls of the specimen and the confined space. This is expected to provide the complete at-rest $K_{0}$ condition.

The modifications to overcome the aforementioned problems are presented in the next section.

\subsection{HCA specimens}

HCA specimens were $200 \mathrm{~mm}$ high with inner and outer diameters of $D_{i}=50$ and $D_{o}=100 \mathrm{~mm}$, respectively. The $D_{O}-D_{i}$ in this study was relatively high and it might cause the stress distribution in the horizontal cross section of the specimen to be slightly non-uniform. However, as the main objective was comparison between the behavior of cemented and uncemented specimens, the effect could be negligible. Pedestal and loading cap of the hollow cylinder specimens used for application of torsional torque had blades with a protruding length of $4 \mathrm{~mm}$, which were devised to provide the upper and lower fixity of specimens against rotation.

Preparation of the cemented specimens required developing new molds and making use of new provisions. As for the simple shear specimens, providing the conditions of complete fixity and no sliding between the loading platens and precast specimens was the most important issue in construction of molds and artificially cemented specimens. On the other hand, convenience and repeatability of intact removing of the specimens from the long molds (compared to SS specimens) should be maintained.

\section{Modifications of specimen preparation methods}

\subsection{Cemented simple shear specimens}

To resolve the problem of sliding between the two ends of specimen and top/bottom platens, the pedestal and the top loading caps were modified along with the support conditions of the ends of specimens. To

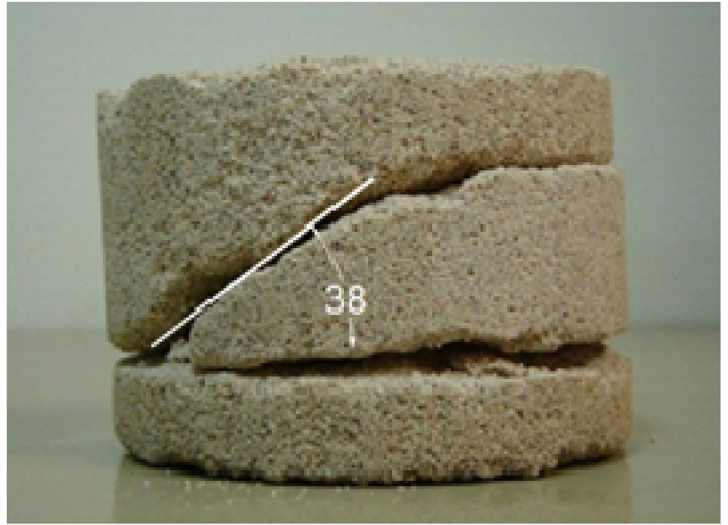

Figure 2. Photo of the shear and slip planes in a specimen with $5 \%$ cement.

perform this, the height of specimens was increased to $50 \mathrm{~mm}$ so that $12 \mathrm{~mm}$ of both ends of the specimen in the upper and lower ends would be fixed by penetrating into the steel rings connected to the pedestal and cap, and the remaining $26 \mathrm{~mm}$ of the specimen was subjected to shear loading as the effective height. More details of modification are presented by Eghbali and Fakharian [32].

The solution to the second problem, to provide the complete all-around pressure and at-rest $K_{0}$ condition, was more challenging. The inner diameter of steel rings, which provided the fixity at both ends of the specimen (connected to the new modified cap and pedestal), was reduced to the inner diameter of the existing 2-mm thick aluminum rings. Then, a trial and error procedure was performed to adopt the best method for preparing prefabrication split molds, details of which are presented by Eghbali \& Fakharian [32] and Eghbali [33].

In brief, it can be expressed that construction of cemented specimens was performed using aluminum as the split mold material and, then, a chemically nonreactive rubber "talcose" coating was applied inside the mold.

Figure 2 shows a specimen at failure with $5 \%$ of cement. The shear line drawn on the specimen shows an approximate angle of $38^{\circ}$ within the horizontal fixity boundaries, complying quite well with the behavior of brittle materials under shear loading [34]. This indicates a rather complete development of failure planes through the specimen.

\subsection{Cemented HCA specimens}

According to the previous experiences from SSA cemented specimens to prevent formation of chemical bonding between cement and metal parts, all the pieces in HCA specimens including caps, external mold, and the six-piece internal mold (except the middle bolt, which was made of stainless steel) were made of Teflon. The appearance of various parts of this mold was 


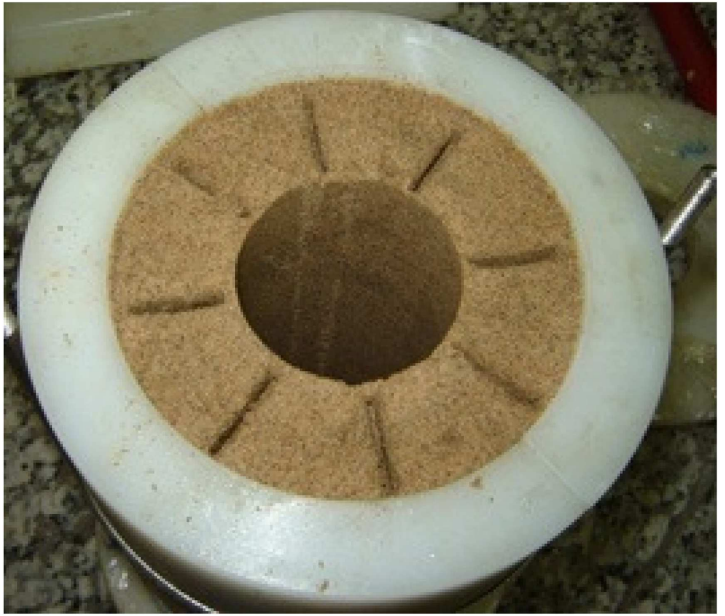

Figure 3. Removal of intact cemented HCA specimen from modified molds of the second try.

similar to that of the accessories required for making specimens of the base soil.

The caps at both ends of the mold were similar to the pedestal of cell in that they had eight blades made of stainless steel, $2 \mathrm{~mm}$ thick, with $4 \mathrm{~mm}$ protrusion.

It is worth mentioning that to ensure a successful intact removal of specimen in this try, a thin nylon cover was used on the ending caps. Figure 3 shows a photograph of specimens made using this method, which were removed safely and soundly from the mold and tested successfully.

Specimens were cured inside cellophane waterproof bags under the water level in a special tank. After this stage, the test was conducted on the specimens under the condition of $b=0.5$ and constant $\alpha$ values of $0,22.5,45,67.5$, or $90^{\circ}$ for static tests and $\alpha= \pm 45^{\circ}$ for the cyclic tests.

After plotting the results and evaluation of recorded images and observations during loading, and giving attention to the shape of the slip planes of specimens, another problem was revealed. In cemented specimens with $\alpha=45^{\circ}$ and $\alpha=67.5^{\circ}$, a lower strength was reached than the real strength in the middle parts away from both ends. In these cases, the major principal stress angle is such that the upper and lower horizontal planes of the specimen are subjected to a high shear stress, which is due to the stress concentration and weaker connection zones between the specimen and the steel blades in these planes. Hence, the results obtained are merely valid up to the failure initiation of the torsional connection with the pedestal and cap (Figure 4).

To resolve the recent problem, which was due to the high strength of cemented specimens, two solutions were proposed. As the first solution, with this assumption in mind that increasing the height of blades and hence deeper penetration into the specimen could result in a more extensive slip surface (similar to an

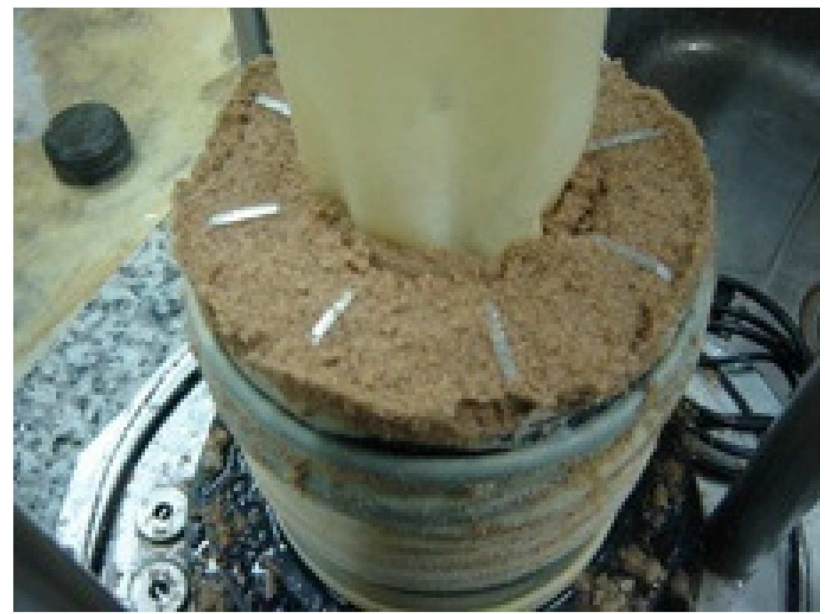

Figure 4. Failure of cemented HCA specimens under loading conditions of $\alpha=45^{\circ}$ and/or $\alpha=67.5^{\circ}$.

inverse shear key), the height of mold and cell blades was increased by $6 \mathrm{~mm}$ so that they could penetrate $10 \mathrm{~mm}$ into the specimen. Figure 5 shows the new blades in comparison with the initial blades.

Cemented specimens were made according to the new method and tested after the curing period. Unlike what was expected, increasing the penetration depth of blades did not help with improving the situation in question. Contrarily, more difficulties were encountered during removal of specimens from the mold, which were due to a more contact area with the blades at the ends of the mold; this resulted in the damage to approximately 75 percent of specimens, making them unsuitable for testing.

As the second and last solution, strengthening the specimen by itself at two ends was considered. To do so, the added cement to the upper and lower ends of the specimen in the length of $10 \mathrm{~mm}$ was increased from $3 \%$ to $8 \%$, while the cement amount in the remaining $180 \mathrm{~mm}$ of the specimen was constant at $3 \%$. New specimens were re-prepared using the initial blades with only $4 \mathrm{~mm}$ of penetration and, then, used for conducting the static tests with $\alpha=45^{\circ}$ and $67.5^{\circ}$, and cyclic tests with $\alpha= \pm 45^{\circ}$. This method worked successfully.

To survey the difference among the performances of ending regions in three different methods of making the specimens, a sample stress path plot is shown in Figure 6. As it may be seen, only the specimen constructed using the method of strengthening through "highly cemented endings" had the expected behavior (dilation behavior and higher strength than that of the base soil). The result of the first solution (longer blades) also showed to be far away from expected.

Figure 7 shows photographs of the recently made specimens using the second solution after removal from the mold and completion of the test. As it may be seen in Figure 7(b), the torsional slip plane of the specimen 

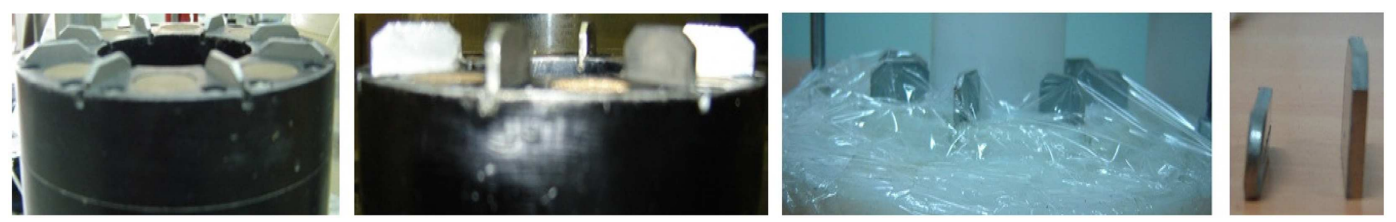

Figure 5. New blades compared with the initial blades.

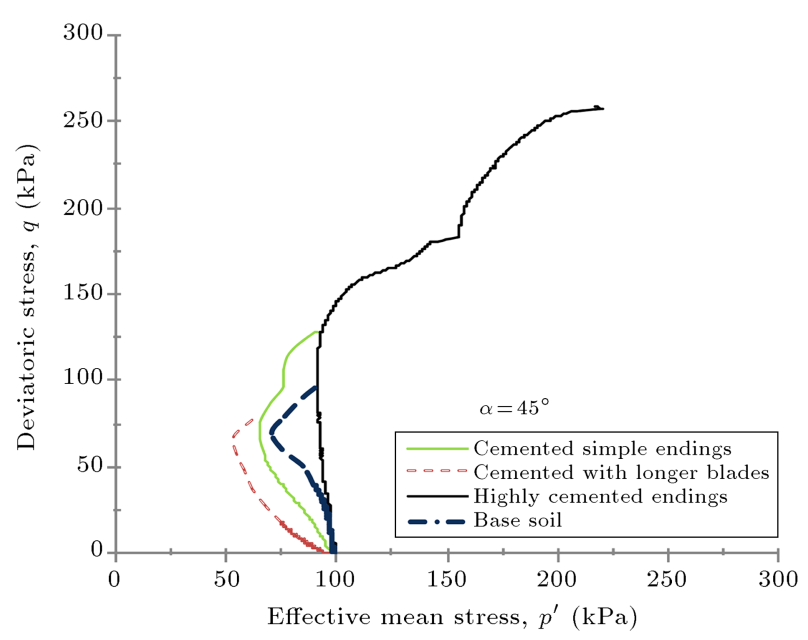

Figure 6. Comparison of the stress-path plots for the prepared cemented HCA specimens using various methods and the base sand specimen.

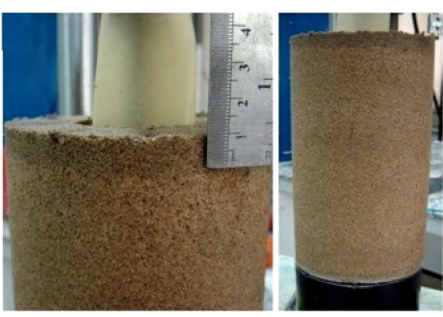

(a)

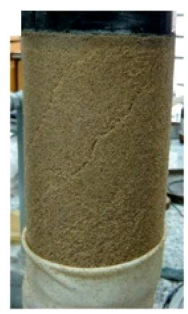

(b)

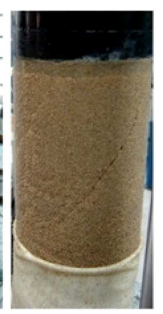

Figure 7. (a) Photo of cemented HCA specimens after removal from the mold, which are strengthened at two $10-\mathrm{mm}$ ends (at the connection regions with adding $\% 8$ cement). (b) Failure planes of the specimen in question at the middle parts after loading.

passed the middle sections, which was indicative of the complete transfer of the strength of materials used in the test.

What should be noted here is the evaluation of the effect of increasing the cement ratio in the upper and lower ends on the strength of the specimen. It should be considered that strengthening the upper and lower ends of the specimen contributes to decreasing the total axial deformation and increasing merely the local axial strength (top and bottom ends), which, due to uniform stress transferring mechanism to middle sections of the specimen, shall not have any impact on total ultimate axial strength. In addition, existing equations for HCA data interpretation $[17,19,21]$ indicate that the axial force and axial stress are equal to zero under loading conditions of $\alpha=45^{\circ}$, and have a small amount for loading at $\alpha=67.5^{\circ}$, which is even in reduction side of the axial pressure in the latter case. Therefore, the major part of the shear stress imposed on the specimen results from application of the torsional moment. Hence, while the effect of specimen non-uniformity on the torsional strength at angles $\alpha=45^{\circ}$ and $\alpha=67.5^{\circ}$ may be neglected with a good approximation, its effect on the behavior of specimens loaded at $\alpha=0^{\circ}, \alpha=22.5^{\circ}$, and $\alpha=90^{\circ}$, in which the axial load and vertical stress have significant values, should be considered.

Under these conditions, equilibrium equations and strength of material relations show that the applied torsional moment will be identically transferred to the mid-height sections of the specimen.

Taking all the above provisions into consideration, cemented HCA specimens under $\alpha=0,22.5$, and $90^{\circ}$ loading conditions were made using the ordinary method, while the method of highly cemented endings was employed for $\alpha=45,67.5^{\circ}$ as well as for cyclic loadings.

\section{Sample test results}

In this section, sample results of the conducted monotonic tests on cemented specimens are presented. Results relating to the clean sand are also given to allow for comparison of the cement effect on the behavior of silica sand.

\subsection{Simple shear tests}

Results of a monotonic test at constant volume (equivalent to undrained condition) on clean sand and 1.5, 3 , and $5 \%$ cemented sands under initial surcharge pressures of 100 and $200 \mathrm{kPa}$ with initial relative density of approximately 10 to $15 \%$ are shown in Figure 8(a) and (b), respectively. In the legend of graphs from left to right, relative density, cement ratio, and initial vertical surcharge load of the specimens are shown, respectively. Significant increase in the strength of cemented specimens even at low cement contents $(1.5 \%)$ is evident, which is indicative of the proper construction and testing method of cemented specimens.

As it may be seen in these plots, behavior of specimens with $5 \%$ cement (high cement content) had 


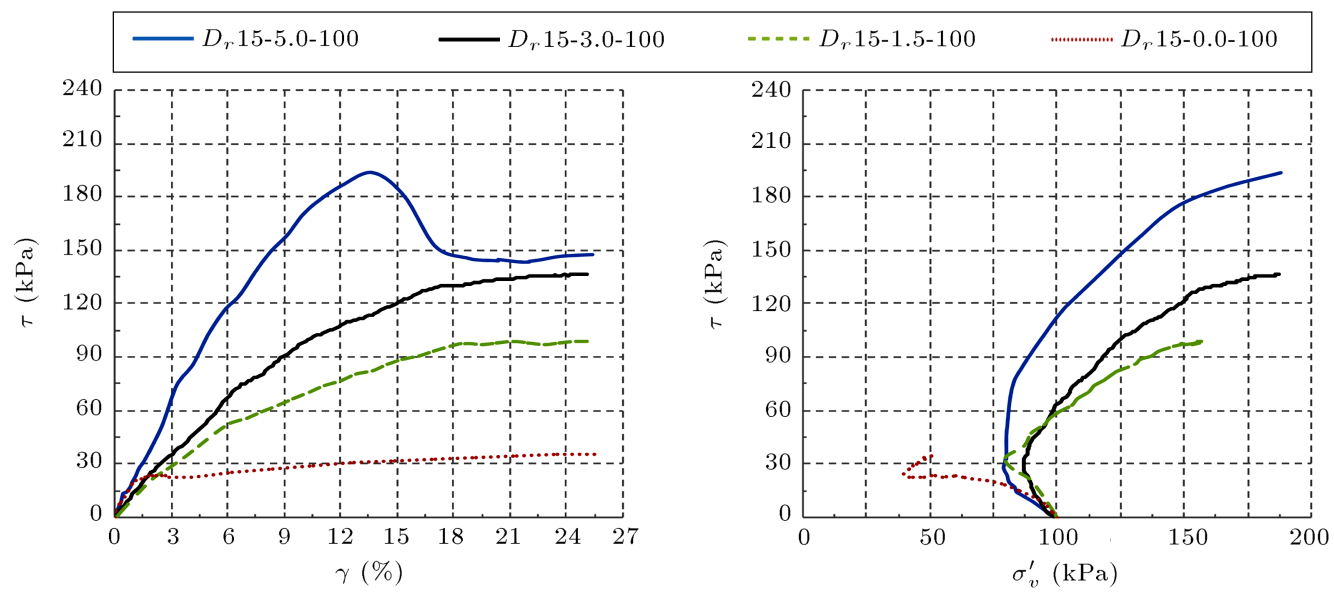

(a)

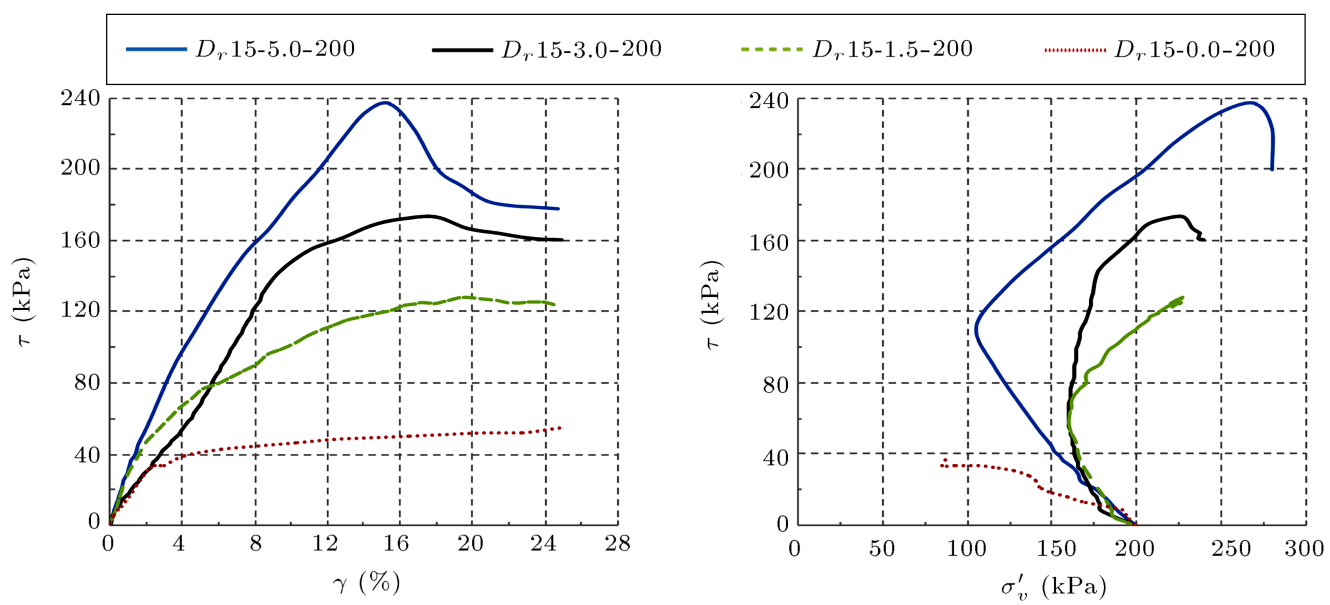

(b)

Figure 8. Stress-strain and stress-path plots in the simple shear test: (a) Initial vertical pressure of $100 \mathrm{kPa}$, and (b) Initial vertical pressure of $200 \mathrm{kPa}$.

a pronounced peak point, after which post-peak softening might be clearly observed. These observations are attributed to the fact that increasing the amount of Portland cement causes the specimen to show more brittle behavior.

Another point which should be noticed is the significant difference considered in the behavior of specimens without cement in comparison with cemented specimens, which had two completely different stresspath conditions. The uncemented clean sand exhibited compressive response whereas all the cemented specimens dilated during shearing.

\subsection{HCA Tests}

Results of conducting the monotonic test on clean sand specimens and 3\% cemented specimens with a relative density of approximately 10 to $15 \%$, which were consolidated at confining pressures of 100 and $200 \mathrm{kPa}$ and loaded under $\alpha=0,22.5,45,67.5$, or $90^{\circ}$ and $b=0.5$ conditions, are shown in Figures 9 to 12 . In the legend of graphs, as shown from left to right, rotation angles of the major principal axis to the vertical $(\alpha)$, cement ratio, and confining pressure of specimens are specified, respectively.

It can be observed as a general rule that the strength of specimens decreases with increase in $\alpha$, while the strength of cemented specimens is much higher than that of clean sand specimens. Unlike clean sand specimens, cemented specimens also showed dilative behavior at all angles of $\alpha$. Moreover, close attention to these plots reveals that adding cement will cause the stress paths related to various angles of $\alpha$ to become more convergent, as shown in Figures 10(a) and 12(a).

It should be noted that extensive experiments were made pursuant to this research using the SS and HCA apparatuses, indicating that adding Portland cement would reduce the inherent anisotropy of sands as a general rule [33].

\section{Conclusions}

Modifications were made in the specimen preparation 


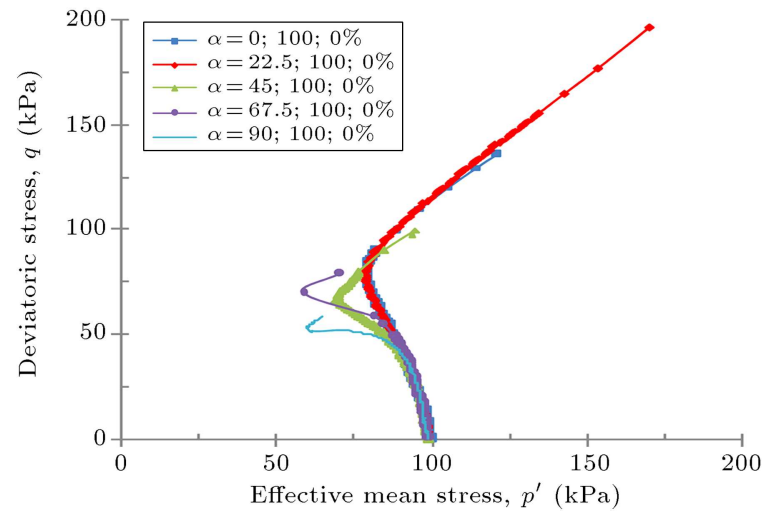

(a)

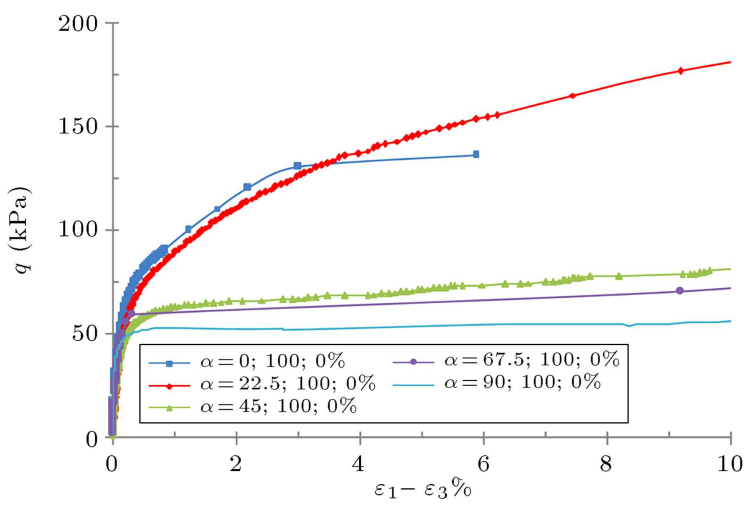

(b)

Figure 9. Plots related to the HCA specimens without cement subjected to a confining pressure of $100 \mathrm{kPa}$ : (a) Stress path $q-p^{\prime}$, and (b) deviator stress versus difference of principal strains.

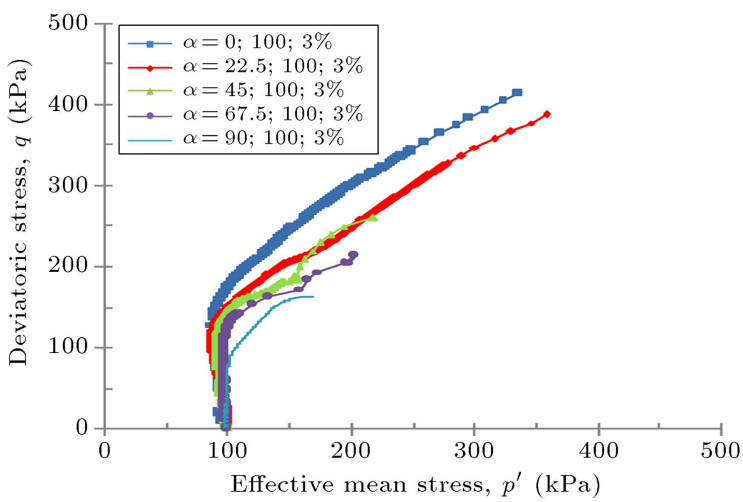

(a)

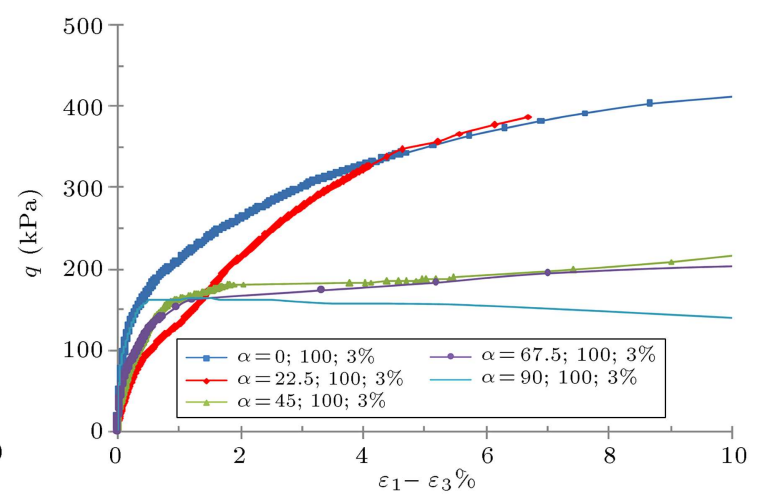

(b)

Figure 10. Plots related to HCA specimens with $3 \%$ cement subjected to a confining pressure of $100 \mathrm{kPa}$ : (a) Stress path $q-p^{\prime}$ and (b) deviator stress versus difference of principal strains.

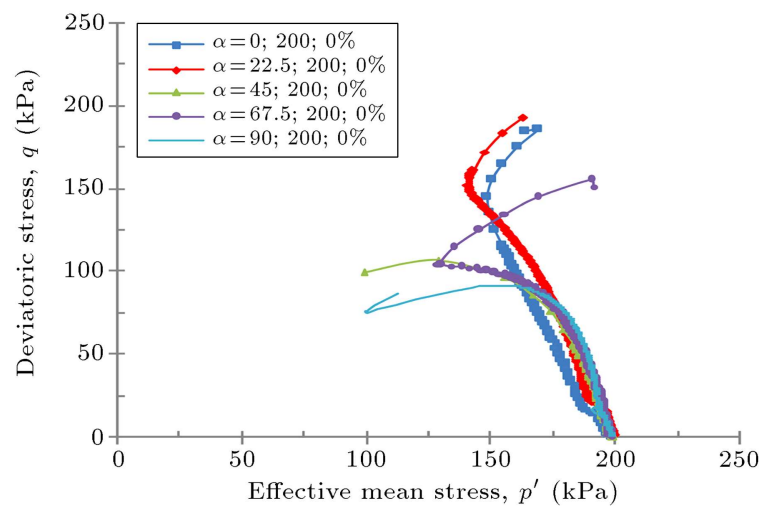

(a)

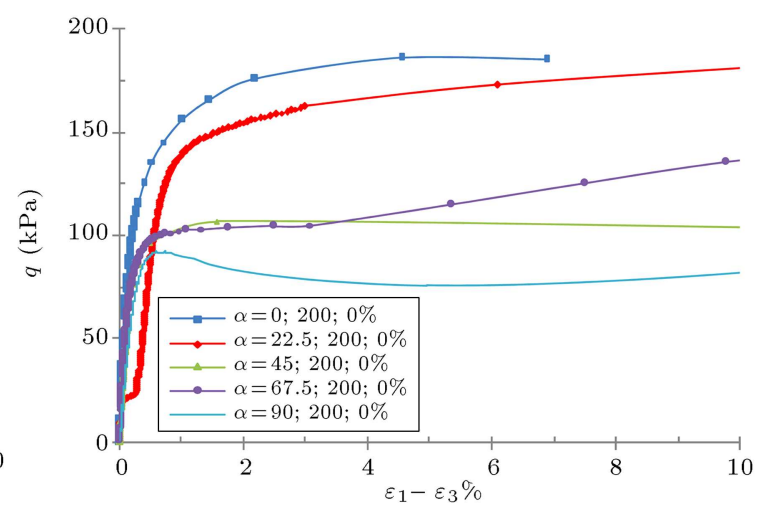

(b)

Figure 11. Plots related to the HCA specimens without cement subjected to a confining pressure of $200 \mathrm{kPa}$ : (a) Stress path $q-p^{\prime}$ and (b) deviator stress versus difference of principal strains.

assembly, molding system, and loading platens of the "simple shear" and "hollow cylinder" apparatuses through an elaborated trial and error process. Specimen molds for preparing clean uncemented granular soils were substantially modified and new methods of making artificially cemented specimens for testing in
SSA and HCA systems were innovated and introduced. The most important findings of the study are summarized as follows:

1. To prepare artificially cemented specimens, various methods were suggested and tried on the basis of 


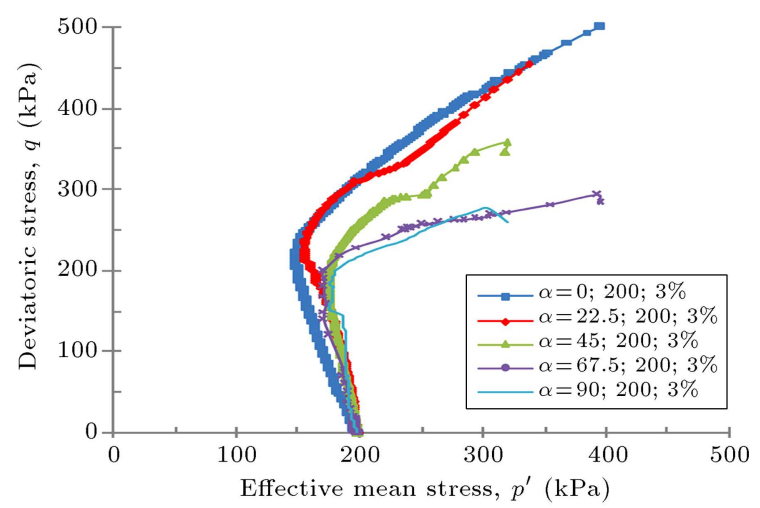

(a)

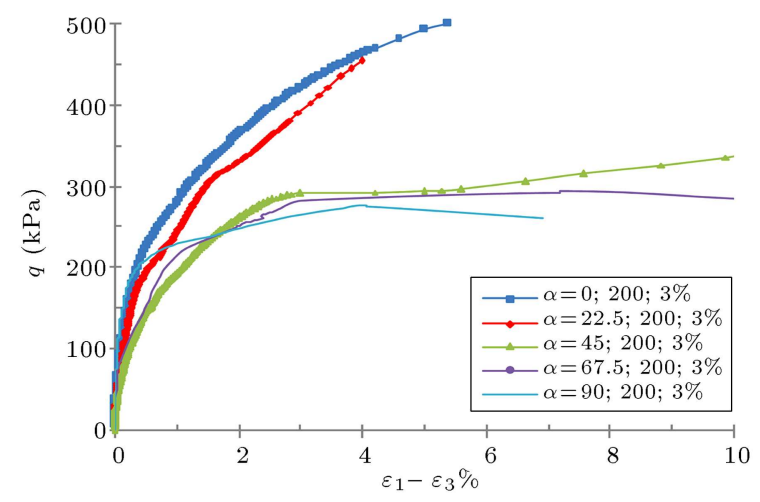

(b)

Figure 12. Plots related to HCA specimens with $3 \%$ cement subjected to a confining pressure of $200 \mathrm{kPa}$ : (a) Stress path $q-p^{\prime}$ and (b) deviator stress versus difference of principal strains.

which practical methods were finally proposed for each of the SSA and HCA systems;

2. In all the evaluated methods, the emphasis was on two issues: a) intact removal of the cemented specimens from the precast molds with the required shape and dimensions after the curing period, and b) preventing the sliding between specimen surface and loading platens (top and bottom) to develop full strength of cemented specimens to achieve a general shear failure condition (instead of local failure along the contact surfaces of loading platens and specimen);

3. In SSA specimens, using metal rings around the top and bottom of the specimen to ensure anti-rotation connections and using aluminum split molds with a rubber talcose coating inside the mold, which was chemically non-reactive, were the solutions to cemented specimen preparations;

4. In HCA specimens, the most important innovation was strengthening both ends of the specimens by adding more cement to ensure that local failure would not occur near the contact surfaces;

5. Significant increase in strength of cemented specimens compared to the base soil and development of shear bands in 3 and $5 \%$ cemented specimens indicated the proper preparation and shearing of cemented specimens in both SSA and HCA systems;

6. The uncemented clean sands exhibited compressive response, whereas all the cemented specimens dilated during shearing;

7. Generally, the strength of both uncemented and cemented specimens decreases with increase in $\alpha$, while the strength of cemented specimens is much more than that of clean sand specimens. Unlike clean sand specimens, cemented specimens show dilative behavior at all $\alpha$ angles;
8. Adding cement causes the stress paths relative to various $\alpha$ angles to become more convergent. This is an indication that the cement mixture reduces the anisotropy of the sand-cement mixtures.

\section{References}

1. Dupas, J.M. and Pecker, A. "Static and dynamic properties of sand-cement", J. Geotech. Engrg. Div. $A S C E, \mathbf{1 0 5}$ (GT3), pp. 419-436 (1979).

2. Haeri, S.M., Hosseini, S.M. and Toll, D.G. "The behavior of an artificially cemented sandy gravel", Geotechnical \& Geological Engineering, Springer, 23, pp. 537-560 (2005a).

3. Haeri, S.M., Hamidi, A. and Tabatabaee, N. "The effect of gypsum cementation on the mechanical behavior of gravelly sands", Geotechnical Testing Journal, 28(4), pp. 1-11 (2005b).

4. Hamidi, A. and Haeri, S.M. "Stiffness and deformation characteristics of a cemented gravely sand", International Journal of Civil Engineering, 6(3), pp. 159-173 (2008).

5. Schnaid, F., Prietto, P.D.M. and Consoli, N.C. "Characterization of cemented sand in triaxial compression", J. Geotech. And Geoenv. Engng. ASCE, 127(10), pp. 857-868 (2001).

6. Consoli, N.C., Prietto, P.D.M. and Ulbrich, L.A. "Influence of fiber and cement addition on behavior of sandy soil", J. Geotech. And Geoenv. Engng. ASCE, 124(12), pp. 1211-1214 (1998).

7. Consoli, N.C., Rotta, G.V. and Prietto, P.D.M. "Influence of curing under stress on the triaxial response of cemented soils", Geotechnique, 50(1), pp. 99-105 (2000).

8. Consoli, N.C., Rotta, G.V. and Prietto, P.D.M. "Yielding-compressibility-strength relationship for an artificially cemented soil cured under stress", Geotechnique, 56(5), pp. 69-72 (2006). 
9. Consoli, N.C., Foppa, D., Festugato, L. and Heineck, K.S. "Key parameters for strength control of artificially cemented soils", J. Geotech. and Geoenv. Engng. $A S C E, \mathbf{1 3 3}(2)$, pp. 197-205 (2007).

10. Consoli, N.C., Cruz, R.C., Floss, M.F. and Festugato, L. "Parameters controlling tensile and compressive strength of artificially cemented sand", J. Geotech. And Geoenv. Engrg, 136(5), pp. 759-763 (2010).

11. Rotta, G.V., Consoli, N.C., Prietto, P.D.M., Coop, M.R. and Graham, J. "Isotropic yielding in an artificially cemented soil cured under stress", Geotechnique, 53(5), pp. 493-501 (2003).

12. Malandraki, V. and Toll, D.G. "Triaxial tests on weakly bonded soil with changes in stress path", $J$. Geotech. and Geoenv. Engng. ASCE, 127(3), pp. 282291 (2001).

13. Boulanger, R.W., Chan, C.K., Seed, H.B., Seed, R.B. and Sousa, J.B. "A low-compliance bi-directional cyclic simple shear apparatus", Geotechnical Testing Journal, 16(1), pp. 36-45 (1993).

14. Vaid, Y.P. and Finn, W.D.L. "Static shear and liquefaction potential", J. Geotech. Engrg. Div., ASCE, 105(10), pp. 1233-1246 (1979).

15. Dyvik, R., Berre, T., Lacasse, S. and Raadim, B. "Comparison of truly undrained and constant volume direct simple shear tests", Geotechnique, 37(1), pp. 310 (1987).

16. Ishihara, K. and Yamazaki, F. "Cyclic simple shear tests on saturated sand in multi-directional loading", Soils and Foundations, 20(1), pp. 45-59 (1980).

17. Vaid, Y.P., Sayao, A., Hou, E. and Negussey, D. "Generalized stress-path-dependent soil behavior with a new hollow cylinder torsional apparatus", Can. Geotech. J., 27, pp. 601-616 (1990).

18. Yoshimine, M., Ishihara, K. and Vargas, W. "Effects of principal stress direction and intermediate principal stress on undrained shear behavior of sand", Soils and Foundations, 38(3), pp. 179-188 (1998).

19. Yang, Z.X., Li, X.S. and Yang, J. "Undrained anisotropy and rotational shear in granular soil", Geotechnique, 57(4), pp. 371-384 (2007).

20. Bahadori, H., Ghalandarzadeh, A. and Towhata, I. "Effect of non plastic silt on the anisotropic behavior of sand", Soils and Foundations, 48(4), pp. 531-545 (2008).

21. Kumruzzaman, Md. and Yin, J.H. "Influences of principal stress direction and intermediate principle stress on the stress-strain-strength behaviour of completely decomposed granite", Can. Geotech. J., 47, pp. 164179 (2010).

22. Sivathayalan, S., Manmatharajan, V. and Logeswaran, P. "Hollow cylinder torsional shear tests to evaluate the role of principal stress directions on cyclic resistance", CGS, Geotechnical Conference, Pan-Am (2011).
23. Baziar, M.H. and Sharafi, H. "Assessment of silty sand liquefaction potential using hollow torsional tests an energy approach", Soil Dynamics and Earthquake Engineering, 31(7), pp. 857-865 (July, 2011).

24. Baziar, M.H., Shahnazaria, H. and Sharafi, H. "A laboratory study on the pore Pressure generation model for Firouzkooh silty sands using hollow torsional tests", International Journal of Civil Engineering, 9(2), pp. 126-134 (June, 2011).

25. Jafarian, Y., Towhata, I., Baziar, M.H., Noorzad, A. and Bahmanpoor, A. "Strain energy based evaluation of liquefaction and residual pore water pressure in sands using cyclic torsional shear experiments", Soil Dynamics and Earthquake Engineering, 35, pp. 13-28 (2012).

26. Keyhani, R. and Haeri, S.M. "Evaluation of the effect of anisotropic consolidation and principle stress rotation on undarined behavior of silty sands", Scientia Iranica, Transactions: A, 20(6), pp. 1637-1653 (2013).

27. Boulanger, R.W. and Seed, R.B. "Liquefaction of sand under bidirectional monotonic and cyclic loading", $J$. of Geotechnical Engrg., ASCE, pp. 870-878 (1995).

28. Nayeri, A. and Fakharian, K. "Study on pullout behavior of uniaxial HDPE geogrids under monotonic and cyclic loads", International Journal of Civil Engineering, 7(4), pp. 211-223 (2009).

29. Movahed, V., Sharafi, H., Baziar, M. and Shahnazari, H. "Comparison of strain controlled and stress controlled tests in evaluation of fines content effect on liquefaction of sands-an energy approach", GeoFrontiers, pp. 1804-1814 (2011).

30. Ismail, M.A., Joer, H.A. and Randolph, M.F. "Sample Preparation technique for artificially cemented soils", Geotechnical Testing Journal, 23(2), pp. 171177 (2000).

31. Ladd, R.S. "Preparing test specimens using under compaction", Geotechnical Testing Journal, 1(1), pp. 16-23 (1978).

32. Eghbali, A.H. and Fakharian, K. "Effect of principal stress rotation in cement-treated sands using triaxial and simple shear tests", International Journal of Civil Engineering, Transaction B: Geotechnical Engineering, 12(1), pp. 1-14 (2014).

33. Eghbali, A.H. "Effect of cement addition on silica sand behavior under different static and dynamic stress paths", Ph.D. Thesis, Dept. of Civil and Environment Engineering, AmirKabir University of Technology, Tehran, Iran (2012) (In Persian).

34. Beer, F.P. and Johnston, E.R., Mechanics of Materials, Chapter 2, McGraw-Hill (1992).

\section{Biographies}

Kazem Fakharian received his BSc and MSc degrees in Civil Engineering and Geotechnical Engineering, respectively, from Amirkabir University of Technology (Tehran Polytechnic) during 1980s. Then, he 
received his $\mathrm{PhD}$ degree in Geotechnical Engineering from University of Ottawa, Canada, in 1996. His main contribution during the $\mathrm{PhD}$ work was developing a new 3D Simple Shear Type Apparatus for Cyclic Interface testing between soil and structural materials.

He is presently an Associate Professor at Amirkabir University, Department of Civil and Environmental Engineering. His main research topics are behavior of soil using advanced soil testing apparatuses such as cyclic triaxial, cyclic simple shear, and cyclic hollow cylinder; study of anisotropy of geomaterials; development of advanced soil testing equipment; and pile foundations, a field in which he has done many studies such as effect of soil setup on bearing capacity of driven piles in clay, pile group modeling, piled-raft foundations, and laterally loaded piles. Dr. Fakharian has also made many contracts to perform projects with industries in piling engineering of which a large database of dynamic and static loads has been provided. As he has made big contributions to optimization of pile foundations in large industrial projects across the country, the vast database collected from static and dynamic load tests are being used as research data for graduate students.

Moreover, his other topic of interest within the past decade has been the study of seismic behavior of reinforced bridge abutments as well as experimental study of reinforcing materials such as geogrids subjected to monotonic and cyclic loads in pullout box carried out in the soil dynamics lab of Amirkabir University.

Amir Hossein Eghbali received his BSc degree in Civil Engineering from Sharif University of Technology during 1998-2003. Then, he received MSc and PhD degrees in Geotechnical Engineering from Khaje Nasir University of Technology (KNTU) and Amirkabir University of Technology, respectively, in 2006 and 2012. $\mathrm{He}$ is presently an Assistant Professor at Islamshahr
Branch, Islamic Azad University, Department of Engineering. His main research topics are the study of behavior of soil, especially using advanced soil testing apparatus. Also, study of soil retaining structures and numerical analysis are his other topics of interest.

Dr. Eghbali's main contribution during the $\mathrm{PhD}$ work was introducing new methods for testing artificially cemented sand in Simple Shear Apparatus and Hollow Cylinder Apparatus and studying the behavior of artificially cemented sand under static and dynamic loading (different stress paths) and anisotropy.

Sara Heidarie Golafzani received the BS degree in Civil Engineering and MSc degree in Geotechnical Engineering from Amirkabir University of Technology, Tehran, Iran, in 2008 and 2011, respectively. She is currently a PhD candidate in Geotechnical Engineering at University of Guilan, Rasht, Iran. She was directly admitted to the Geotechnical Engineering MSc course at Amirkabir University of Technology with honors in 2008. She was ranked the second in the first National Concrete Competition (Amirkabir University of Technology) in December 2007. She was a jury committee member in the second and third National Concrete Competitions (Amirkabir University of Technology) in 2008 and 2009, respectively.

Mohammad Reza Khanmohammadi received his BSc degree with honors (first rank) in Civil Engineering from Amirkabir University of Technology, Tehran, Iran, in 2008. He was accepted for MSc and $\mathrm{PhD}$ courses with honors at Amirkabir University of Technology; he received his MSc degree in Geotechnical Engineering in 2011 with the first rank among graduate students. $\mathrm{He}$ is currently a $\mathrm{PhD}$ candidate in Geotechnical Engineering. For the $\mathrm{PhD}$ thesis, he is researching on pile installation effects on soil stress state and bearing capacity in clays. 